\title{
Impact of practice size on delivery of diabetes care before and after the Quality and Outcomes Framework implementation
}

\author{
Abd A Tahrani, Mary McCarthy, Jojo Godson, Sarah Taylor, \\ Helen Slater, Nigel Capps, Probal Moulik and Andrew F Macleod
}

\begin{abstract}
General practice characteristics are important for healthcare providers to maximise outcomes. Although different aspects of general practice characteristics have been studied previously, the impact of practice size on the delivery of care has been sparsely studied, particularly in relation to diabetes care. This brief report presents a longitudinal study in Shropshire (66 practices, 16858 patients with diabetes) to assess the impact of practice size on diabetes care before and after implementation of the Quality and Outcomes Framework (QOF). Achievement of glycaemic control targets was better before the QOF for larger as compared to smaller practices $(P=0.02$ and $P=0.003$ for haemoglobin $\mathrm{A} 1 \mathrm{c}[\mathrm{HbA} 1 \mathrm{c}] \leq 7.4 \%$ and $10 \%$ respectively). This difference disappeared following QOF implementation. Repeated measures analysis showed significant improvement in achieving glycaemic control targets following QOF implementation in both large and small practices $(P<0.001$ for $\mathrm{HbA} 1 \mathrm{c} \leq 7.4 \%$ and $10 \%)$. The study failed to reveal an impact of practice size on achieving the $\mathrm{HbA} 1 \mathrm{c}$ target $\leq 7.4 \%(P=0.1)$ by this analysis. However, it did show an impact on reaching the target of HbA1c $\leq 10 \%(P=0.04)$ in favour of smaller practices. There was a significant difference in favour of smaller practices for achievement of prescription of angiotensin-converting enzyme inhibitors $(P=0.001)$.

Keywords

pay for performance; practice size; quality and outcomes framework.
\end{abstract}

\section{INTRODUCTION}

There has been wide interest in the use of financial incentives to improve clinical care and outcomes, not least in the UK. ${ }^{1,2}$ The Quality and Outcomes Framework (QOF) was introduced in April 2004 in the UK to reward practices for delivering evidencebased clinical and organisational quality care. ${ }^{3}$

The relationship between practice characteristics and clinical outcomes is of interest to healthcare providers. One characteristic is practice size. This has been sparsely studied in the literature, particularly in relation to diabetes care. Studies that have assessed the impact of practice size on diabetes care in the UK are small in number, and show conflicting results. ${ }^{4-6}$

Significant improvements have previously been shown in all QOF quality indicators of diabetes care

AA Tahrani, MD, MRCP, MMedSci, clinical lecturer in diabetes and endocrinology, Division of Medical Sciences, University of Birmingham and Birmingham Heartlands Hospital, Birmingham. M McCarthy, MRCGP, GP, Belvedere Medical Practice, Shrewsbury. J Godson, service redesign manager, Shropshire County PCT, Shrewsbury. S Taylor; knowledge specialist; $\boldsymbol{H}$ Slater, assistant commissioner, Telford and Wrekin PCT, Telford. N Capps, FRCPath, consultant chemical pathologist, Princess Royal Hospital and Royal Shrewsbury Hospital, Shrewsbury. P Moulik, MD, FRCP, consultant in diabetes and endocrinology; AF Macleod, MD, FRCP, consultant in diabetes and endocrinology, Royal Shrewsbury Hospital, Shrewsbury.

Address for correspondence

Dr Abd Tahrani, University of Birmingham, Birmingham Heartlands Hospital, Diabetes and Endocrinology, Bordsley Green East, Birmingham, B9 5SS.

E-mail: a.a.tahrani@bham.ac.uk

Submitted: 8 January 2008; Editor's response: 10 March 2008; final acceptance: 22 April 2008.

(c)British Journal of General Practice 2008; 58: 576-579.

DOI: 10.3399/bjgp08X319729 
following the implementation of the QOF. The aim of this study is to assess the impact of practice size on diabetes care in Shropshire before and after the QOF.

\section{METHOD}

\section{Setting}

Shropshire is a well-defined geographical area with a stable population of 460000 in both rural and urban areas. Some $82 \%$ of the 16858 patients with diabetes are managed in the community with general guidance from the specialist diabetes service. The same IT system is used in all but two practices, and data are downloaded from one central laboratory. All but one practice took part in the National Diabetes Audit prior to the QOF implementation in April 2004. The research had access to the whole population, that is, all relevant data from all practices in Shropshire.

\section{The study}

An observational longitudinal study was conducted. Data obtained included the diabetes register size and the number of patients achieving each quality indicator. The proportion of patients achieving QOF quality indicators in Shropshire before and after QOF implementation was calculated. These data were received from the primary care trusts already anonymised with coded identity, and hence the investigators could not identify any particular practice or patient. The researchers had access to data at patient level before the QOF, and at practice level after the QOF.

Methods regarding the acquisition of and handling of data, and removal of the bias of exception recording are described in the authors' previous paper. $^{7}$

Practices were divided into larger and smaller units by the national average of number of patients per practice (5500). The average number of patients per practice in Shropshire is 7045 .

\section{Statistical analysis}

Statistical analysis was done using SPSS software. Data are presented as the mean proportion of patients achieving each quality indicator at all time points. Independent sample $t$-test was used to calculate the $P$-value and $95 \%$ confidence intervals

\section{How this fits in}

Family practice characteristics might be related to the achievement of QOF quality indicators. Practice size need not be a factor in planning diabetes care in the community at the moment.
Table 1. Summary of results of the quality indicators in larger and smaller family practices.

\begin{tabular}{|c|c|c|c|c|c|c|}
\hline & \multicolumn{2}{|c|}{ Small } & \multicolumn{2}{|c|}{ Large } & \multirow[b]{2}{*}{$P$-value } & \multirow[b]{2}{*}{$95 \% \mathrm{Cl}$} \\
\hline & Mean, \% & SD & Mean, \% & SD & & \\
\hline \multicolumn{7}{|l|}{ Organisational quality indicators } \\
\hline \multicolumn{7}{|l|}{ April 2004} \\
\hline BMI record & 71 & 12 & 74 & 9 & 0.18 & -9 to 2 \\
\hline Blood pressure record & 86 & 7 & 89 & 4 & 0.05 & -6 to 0 \\
\hline $\mathrm{HbA} 1 \mathrm{c}$ record & 73 & 16 & 77 & 15 & 0.25 & -12 to 3 \\
\hline Creatinine record & 79 & 10 & 83 & 7 & 0.09 & -8 to 1 \\
\hline Total cholesterol record & 78 & 7 & 78 & 8 & 0.72 & -3 to 5 \\
\hline Microalbuminuria record & 8 & 12 & 5 & 12 & 0.32 & -3 to 9 \\
\hline Eye exam record & 40 & 22 & 52 & 18 & 0.02 & -22 to -2 \\
\hline Peripheral pulses exam record & 23 & 26 & 22 & 22 & 0.80 & -10 to 13 \\
\hline Neuropathy test record & 23 & 26 & 22 & 22 & 0.80 & -10 to 13 \\
\hline Smoking status record & 43 & 14 & 45 & 15 & 0.65 & -9 to 6 \\
\hline \multicolumn{7}{|l|}{ April 2005} \\
\hline BMI record & 88 & 12 & 88 & 5 & 0.88 & -4 to 5 \\
\hline Blood pressure record & 97 & 3 & 97 & 2 & 0.86 & -1 to 2 \\
\hline $\mathrm{HbA} 1 \mathrm{c}$ record & 93 & 5 & 93 & 3 & 0.53 & -1 to 3 \\
\hline Creatinine record & 93 & 4 & 93 & 4 & 0.90 & -2 to 2 \\
\hline Total cholesterol record & 93 & 4 & 92 & 4 & 0.30 & -1 to 3 \\
\hline Microalbuminuria record & 71 & 20 & 68 & 21 & 0.46 & -6 to 14 \\
\hline Eye exam record & 80 & 11 & 80 & 10 & 0.92 & -5 to 5 \\
\hline Peripheral pulses exam record & 79 & 11 & 79 & 12 & 0.92 & -6 to 5 \\
\hline Neuropathy test record & 77 & 11 & 78 & 12 & 0.66 & -7 to 5 \\
\hline Smoking status record & 96 & 5 & 95 & 3 & 0.42 & -1 to 3 \\
\hline \multicolumn{7}{|l|}{ April 2006} \\
\hline BMI record & 90 & 6 & 89 & 5 & 0.55 & -2 to 4 \\
\hline Blood pressure record & 97 & 2 & 97 & 2 & 0.85 & -1 to 1 \\
\hline $\mathrm{HbA} 1 \mathrm{c}$ record & 94 & 3 & 94 & 3 & 0.75 & -1 to 2 \\
\hline Creatinine record & 94 & 3 & 94 & 3 & 0.71 & -1 to 2 \\
\hline Total cholesterol record & 94 & 3 & 93 & 3 & 0.18 & 0 to 2 \\
\hline Microalbuminuria record & 80 & 11 & 75 & 17 & 0.14 & -2 to 13 \\
\hline Eye exam record & 85 & 7 & 84 & 6 & 0.74 & -3 to 4 \\
\hline Peripheral pulses exam record & 81 & 10 & 80 & 12 & 0.57 & -4 to 7 \\
\hline Neuropathy test record & 83 & 9 & 80 & 12 & 0.32 & -3 to 8 \\
\hline Smoking status record & 96 & 5 & 95 & 3 & 0.48 & -1 to 3 \\
\hline \multicolumn{7}{|l|}{ Clinical quality indicators } \\
\hline \multicolumn{7}{|l|}{ April 2004} \\
\hline $\mathrm{HbA} 1 \mathrm{c} \leq 7.4 \%$ & 36 & 18 & 46 & 12 & 0.02 & -17 to -2 \\
\hline $\mathrm{HbA} 1 \mathrm{c} \leq 10 \%$ & 64 & 16 & 73 & 6 & 0.003 & -15 to -3 \\
\hline Blood pressure $\leq 145 / 85 \mathrm{mmHg}$ & 48 & 12 & 46 & 10 & 0.48 & -3 to 7 \\
\hline Total cholesterol $\leq 5 \mathrm{mmol} / \mathrm{l}$ & 46 & 10 & 48 & 8 & 0.40 & -6 to 3 \\
\hline \multicolumn{7}{|l|}{ April 2005} \\
\hline $\mathrm{HbA} 1 \mathrm{c} \leq 7.4 \%$ & 47 & 10 & 49 & 9 & 0.39 & -7 to 3 \\
\hline $\mathrm{HbA} 1 \mathrm{c} \leq 10 \%$ & 84 & 8 & 85 & 5 & 0.48 & -4 to 2 \\
\hline Blood pressure $\leq 145 / 85 \mathrm{mmHg}$ & 63 & 11 & 60 & 10 & 0.25 & -2 to 8 \\
\hline Total cholesterol $\leq 5 \mathrm{mmol} / \mathrm{l}$ & 64 & 8 & 65 & 9 & 0.80 & -5 to 4 \\
\hline ACE inhibitors & 94 & 10 & 87 & 14 & 0.08 & -1 to 13 \\
\hline Smoking cessation advice & 95 & 8 & 94 & 6 & 0.56 & -2 to 4 \\
\hline Flu vaccination & 76 & 8 & 75 & 6 & 0.52 & -2 to 4 \\
\hline \multicolumn{7}{|l|}{ April 2006} \\
\hline $\mathrm{HbA} 1 \mathrm{c} \leq 7.4 \%$ & 61 & 7 & 62 & 8 & 0.67 & -5 to 3 \\
\hline $\mathrm{HbA} 1 \mathrm{c} \leq 10 \%$ & 88 & 5 & 88 & 4 & 0.72 & -2 to 2 \\
\hline Blood pressure $\leq 145 / 85 \mathrm{mmHg}$ & 64 & 9 & 66 & 8 & 0.34 & -6 to 2 \\
\hline Total cholesterol $\leq 5 \mathrm{mmol} / \mathrm{l}$ & 71 & 7 & 71 & 6 & 0.62 & -2 to 4 \\
\hline ACE inhibitors & 96 & 7 & 90 & 9 & 0.001 & 3 to 11 \\
\hline Smoking cessation advice & 97 & 5 & 95 & 4 & 0.24 & -1 to 4 \\
\hline Flu vaccination & 80 & 6 & 79 & 5 & 0.52 & -2 to 4 \\
\hline
\end{tabular}

Results represent the mean percentage (and standard deviation) of patients achieving each indicator in each family practice, and the $95 \%$ confidence interval) for the difference in means of the proportion of patients achieving each quality indicator between larger and smaller practices at the different time points. $A C E=$ angiotensin-converting enzyme; $B M I=$ body mass index. 


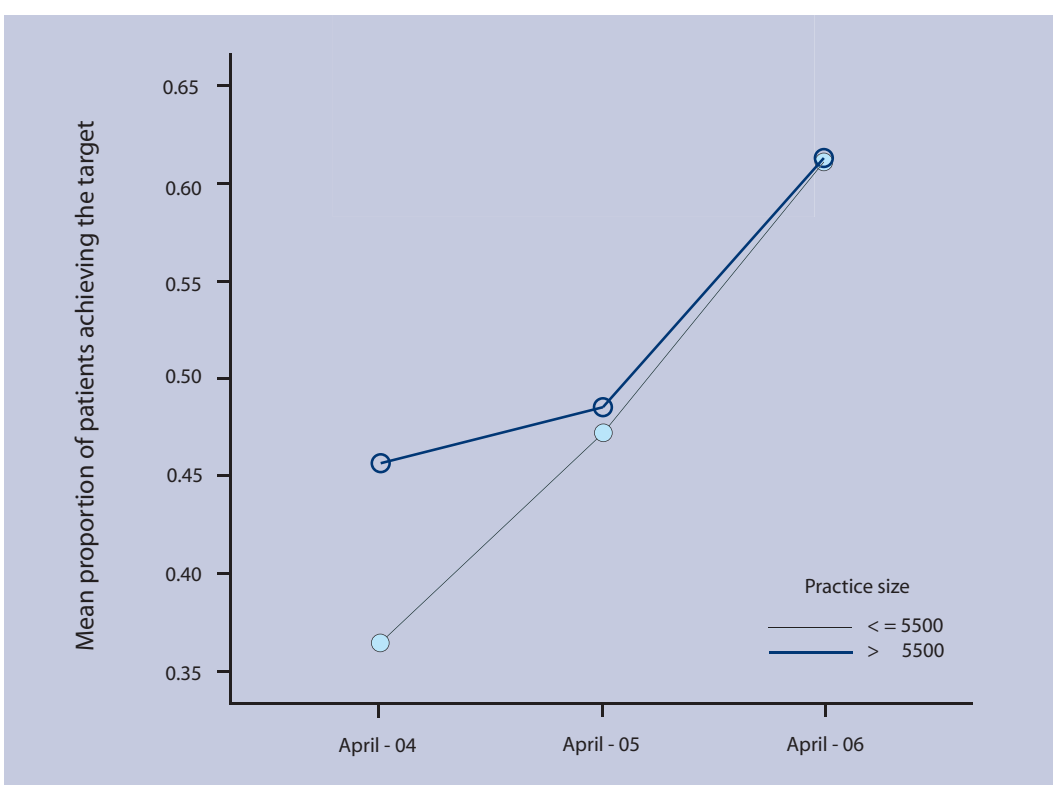

Figure 1. The mean proportion of patients achieving $\mathrm{HbA1c} \leq 7.4 \%$ in small and large practices before (April 2004) and after (April 2005 and April 2006) QOF implementation.
(Cls) for the difference in means of the proportion of patients achieving each quality indicator between larger and smaller practices at the different time points. Repeated measures analysis was used to assess the relation between practice size and the mean proportion of patients achieving glycaemic control targets over the study period.

\section{RESULTS}

A summary of the results is given in Table 1. The majority of quality indicators showed no difference between larger and smaller practices prior to QOF implementation. The exceptions were records of eye examination and glycaemic control targets, which were better in larger practices. These differences were ameliorated following QOF implementation. After the implementation of QOF the majority of quality indicators showed no statistically significant difference between smaller and larger practices. The exception was a statistically significant difference in the prescription of angiotensin-converting enzyme (ACE) inhibitors in favour of smaller practices.

Figure 1 summarises the impact of practice size on glycaemic control at all time points. Repeated measures analysis showed a significant improvement in achieving glycaemic control targets following QOF implementation in both large and small practices $(P<0.001$ for haemoglobin $\mathrm{A} 1 \mathrm{c}$ $[\mathrm{HbA} 1 \mathrm{c}] \leq 7.4 \%$ and $10 \%)$. The study failed to reveal an impact of practice size on achieving the $\mathrm{HbA1c}$ target $\leq 7.4 \%(P=0.1)$ by this analysis. However, it did confirm an impact on reaching the target of $\mathrm{HbA1c} \leq 10 \%(P=0.04)$ in favour of smaller practices. There was a significant difference in favour of smaller practices for achievement of prescription of ACE inhibitors $(P=0.001)$.

\section{DISCUSSION}

\section{Summary of main findings}

All quality indicators showed significant improvement following the QOF. Glycaemic control targets improved in both small and large practices. The magnitude of improvement, however, was greater in smaller practices. It seems that smaller practices 'caught up' with larger practices after QOF implementation. This could imply a direct effect of financial incentives to achieve the same target (and therefore reimbursement) already achieved by some larger practices.

\section{Strengths and limitations of the study}

The study data have their strengths. While the evidence provided in the above-mentioned studies in the post-QOF era is mainly based on comparing QOF scores between different practices, the present data compare the mean proportion of patients achieving each quality indicator. This is important as QOF points are awarded when practices achieve a certain threshold, and hence variation in the proportion of patients achieving a particular target above that threshold will not affect the QOF score. Thus some practices may still have a significantly higher proportion of patients achieving a QOF indicator compared with other practices, but still achieve the same QOF points.

Unlike the other studies, ${ }^{4-6,8}$ the present study has compared the same practices before and after the QOF. This is important, as other factors that affect outcome would have been constant throughout the study period.

This research removed the effect of 'exception reporting', by calculating the proportion of patients out of the total number on the diabetes register in that practice, rather than the denominators provided by the practices. To the best of the authors' knowledge, this study is the first to compare diabetes care and its relation to practice size for the same population of practices before and after the QOF.

\section{Comparison with existing literature}

The evidence of practice size impact on quality of care in the UK before the QOF is conflicting. While some studies showed that practice size had no impact on glycaemic control but smaller practices were more adherent to process of care measures, others showed that patients in larger practices tended to have lower HbA1c.4,5,8 Following QOF implementation, studies suggest that practice size had no impact on diabetes care. ${ }^{6}$

\section{Implications for future research}

In summary, the present data reveal that practice size has had little impact on patients' diabetes care either 
before or following the QOF, and practice size had no impact on achieving blood pressure and total cholesterol targets. However, glycaemic control was less satisfactory in smaller practices before implementing the QOF. This difference disappeared following the QOF, which could suggest an effect of the financial incentive on diabetes care. This research suggests that practice size is not a factor that needs to be taken into account when planning community diabetes care. However, a further examination into the effect of practice size may be appropriate if the current financial incentives undergo significant change.

\section{Funding body}

Not applicable

Ethical approval

Ethical approval was not required

\section{Competing interests}

The authors have stated that there are none

\section{Acknowledgements}

All GP practices in Shropshire, Mrs Ann-Marie Meinhardt, Shropshire County PCT, Telford and Wrekin PCT and Jenny Eden (Shropshire PCT).

\section{Discuss this article}

Contribute and read comments about this article on the Discussion Forum: http://www.rcgp.org.uk/bjgp-discuss

\section{REFERENCES}

1. Epstein AM, Lee TH, Hamel MB. Paying physicians for highquality care. $N$ Engl J Med 2004; 350(4): 406-410.

2. Roland M. Linking physicians' pay to the quality of care - a major experiment in the United Kingdom. N Engl J Med 2004, 351(14): 1448-1454.

3. Department of Health. Investing in general practice, the new general medical services contract. London: Department of Health, 2003. http://www.dh.gov.uk/assetRoot/04/07/86/58/04078658.pdf (accessed 23 Apr 2008).

4. Khunti K, Ganguli S, Baker R, Lowy A. Features of primary care associated with variations in process and outcome of care of people with diabetes. Br J Gen Pract 2001; 51(466): 356-360.

5. Pringle M, Stewart-Evans C, Coupland C, et al. Influences on control in diabetes mellitus: patient, doctor, practice, or delivery of care? BMJ 1993; 306(6878): 630-634.

6. Wang Y, O'Donnell CA, Mackay DF, Watt GC. Practice size and quality attainment under the new GMS contract: a cross-sectional analysis. Br J Gen Pract 2006; 56(532): 830-835.

7. Tahrani AA, McCarthy M, Godson J, et al. Diabetes care and the new GMS contract: the evidence for a whole county. Br J Gen Pract 2007; 57(539): 483-485.

8. Campbell JL, Ramsay J, Green J. Practice size: impact on consultation length, workload, and patient assessment of care. $\mathrm{Br} J$ Gen Pract 2001; 51(469): 644-650. 